\title{
Uso de plantas medicinais como alternativa para o tratamento das cefaleias
}

\section{Use of medicinal plants as an alternative for the treatment of headache}

\author{
Amanda Araújo da Silva, Marcelo Moraes Valença \\ Programa de Pós-graduação em Neuropsiquiatria e Ciências do Comportamento, Departamento de \\ Neuropsiquiatria, Universidade Federal de Pernambuco, Brazil.
}

Silva AA, Valença MM. Uso de plantas medicinais como alternativa para o tratamento das cefaleias. Headache Medicine. 2014;5(2):46-58

\section{RESUMO}

A Organização Mundial de Saúde (OMS) considera a cefaleia a doença neurológica mais comum, que pode gerar incapacidades diversas. Porém, as cefaleias em geral são subestimadas e subnotificadas, dificultando o conhecimento do impacto da doença no panorama da saúde pública. A International Classification of Headache Disorders (ICHD) considera como tipos mais comuns de cefaleia a cefaleia do tipo tensional e enxaqueca, consideradas primárias. $\bigcirc$ tratamento das cefaleias percorre desde o modelo medicamentoso (biomédico) até os métodos tradicionais, com o uso de plantas medicinais. Desde 1980, o termo "Medicina Complementar" foi inserido a fim de compatibilizar os dois modelos. Segundo a Agência Nacional de Vigilância Sanitária (Anvisa), plantas medicinais são as espécies vegetais que são naturais ou cultivadas com a finalidade terapêutica, uma alternativa mais viável de muitas comunidades de tratar e prevenir doenças, além de manter a saúde. $\bigcirc$ uso das plantas ganha força também como fonte de poderes espirituais e mágica. A utilização dessas plantas varia de acordo com o problema de saúde, porém, em todos os casos, há uma falsa crença que os medicamentos naturais não têm contraindicação, o que oferece sérios riscos aos adeptos. Crenças são ideias que se consolidam com o tempo, em que as pessoas consideram mais válidas do que a própria lógica, podendo ter o cunho tendencioso e emocional. $\bigcirc$ objetivo deste estudo foi visitar mercados populares na região do Grande Recife na procura de informação sobre o uso de plantas medicinais para o tratamento da cefaleia.

Palavras-chave: Cefaleia; Plantas medicinais; Crenças

\begin{abstract}
The World Health Organization (WHO) considers headache the most common disease of the nervous system that can generate various disabilities. However, there is an underestimation and underreported hindering the impact of public health. The International Classification of Headache Disorders (ICHD) considers the tension-type headache and migraine as the most common types of primary headache. The treatment of headache has pervaded the medical model (biomedical) extending to the traditional, acknowledged by the use of medicinal plants. From 1980, the term "complementary medicine" was inserted in order to reconcile the two models. According to the National Health Surveillance Agency (Anvisa), medicinal plants are plant species that are natural or cultured with the therapeutic purpose; ease of use as well as to keep the tradition, is the most viable for many communities to treat and prevent diseases, besides maintaining health. The use of plants is beyond cure and includes spiritual power and magic. The use of the plant varies with the health problem, but in all cases, there is a false belief that natural medicines have no contraindication, which offers serious risks to the consumers. Beliefs are ideas that consolidate over time, in that people consider more valid than logic, which may have tendentious and emotional nature. The purpose of this study was to visit popular markets in the Greater Recife region in the search for information on the use of medicinal plants for the treatment of headache.
\end{abstract}

Keywords: Headache; Medicinal plants; Beliefs 


\section{INTRODUÇÃO}

É evidente que o uso da farmacoterapia (administração de drogas) é atualmente a forma de tratamento mais convencional das cefaleias. Apesar disso, a história relata formas de tratamentos adversos que marcaram a história da cefaleia. Entram para a história dois modos de intervenção que marcaram e atravessaram gerações: 1) a cauterização, um tratamento dito perigoso, o qual era aplicado um ferro quente na cabeça do enfermo no momento em que a dor ainda estiver instalada; o paciente que resistir a intervenção era considerado corajoso e vigoroso; e 2) trepanação, que consiste na perfuração do crânio dos seres humanos que ainda encontravam-se vivos, acreditando-se que dali sairia o que estaria fazendo mal; tal prática transpassou do período mesolítico até a Antiguidade e a Idade Média. (1)

Porém outro método menos invasivo e doloroso também fez parte da história, ganhando notoriedade até os dias atuais. $O$ uso e prática das plantas medicinais como forma de tratamento e intervenção na saúde da humanidade dar-se por volta do período paleolítico, no qual os seres humanos tratavam suas doenças e os males através do uso de produtos naturais diversos oriundos de plantas, outros animais e alguns minerais. Estudos apontam que desde a mais tenra época, os humanos já conheciam, pelo método de tentativa e erro, e se utilizavam de propriedades das plantas e suas estruturas (flores, raízes, folhas, sumo, cascas e frutos), utilizando-se delas como anestésicos, psicotrópicos, anti-inflamatórios, antigripais e outros fins medicinais. ${ }^{(2,3)}$

Evidências arqueológicas mostram elaborações farmacológicas dos egípcios, os quais colecionavam uma variação significativa de recursos de origem natural e que através da tecnologia atual há comprovação de efetividade medicamentosa. Grécia, China, Índia e Tibet foram palcos de experimentos de sucesso do uso das plantas há cerca de 3.000 a 1.000 anos. $\bigcirc$ especialista da área possuía destaque por seu conhecimento, poder e influência profissional na sociedade, tornando-se assim figura de respeito e reconhecimento. ${ }^{(3)}$

O século 18 destoa como um novo marco para 0 tratamento das enfermidades pelo uso de plantas medicinais. Foi nesse século em que um naturalista Carolus Linnaeus documentou de forma padronizada as espécies botânicas, características, identificações e suas histórias evolutivas. $\bigcirc$ documento tornou-se marco para a taxo- nomia atual, servindo como base para muitos estudos de botânicos, taxonomistas, herbalistas e estudiosos da área. ${ }^{(3)}$

Mas foi apenas em 1808, com a vinda da corte Real para o Brasil e o decreto de D. João VI para a abertura dos portos às nações amigas, que se encontram os primeiros marcos históricos oficiais da já ciência considerada também brasileira: as primeiras expedições científicas passaram a chegar ao país com o intuito de coletar espécimes da fauna e flora, além de promover o conhecimento. Esse era utilizado pelos fazendeiros, jesuítas e índios que buscaram na natureza alternativas para curar seus males. Médicos, botânicos, zoólogos validaram os estudos sistemáticos da fauna e flora brasileiras, além de legitimarem a notoriedade das plantas medicinais locais, para uso fitoterápico; validade esta que repercutem até os dias atuais, de forma difundida e diversamente contemplada por diversas culturas do país. ${ }^{(4,5)}$

Num contexto atual, nota-se a perpetuação do costume pelo convívio íntimo com a natureza de certos grupamentos culturais, os quais observam em seu dia a dia, exploram e experimentam esse patrimônio de modo constante. A transmissão oral é um importante meio de consolidação do conhecimento, mas a prática em si é o meio mais comum, pois além de manter a tradição, é a alternativa mais viável de muitas comunidades de tratar e prevenir doenças, além de manter a saúde. $\bigcirc$ uso das plantas vai para além da cura das doenças e ganha força na cultura como portadoras de poderes espirituais, crença também perpetuada como tradição, a qual ganha sentido com os rituais religiosos - costume esse valorizado tanto na África quanto no Brasil - em que se acredita que algumas doenças podem ser atribuídas a energia de maus espíritos. Portanto, segundo essas tradições, quando as pessoas são tratadas de alguma enfermidade, há uma estreita relação com os ritos e com o uso das ervas. A utilização da planta varia de acordo com o problema: chás (por infusão ou decocção), pomadas, tinturas, xaropes, garrafadas e até mesmo banho podem ser recomendados - este último, principalmente se a ordem for mística, porém leva-se em consideração que todo tratamento realizado através das plantas medicinais são realizados em conjunto com outras práticas ritualísticas. ${ }^{(5-8)}$

É comum notarmos que a busca pelo tratamento alternativo faz parte da história da humanidade, caracterizando os indivíduos como seres que são capazes de autoajustes culturais, pertinentes às questões que permeiam a época e ética. 


\section{MÉTODO}

O estudo foi realizado em Mercados Públicos nas cidades Recife, Olinda, Igarassu e Paulista situadas na Região Metropolitana do Grande Recife, estado de Pernambuco. Os Mercados vendem as mais diversas especiarias locais, alimentos, artes e artesanatos, além de serem locais de exposição e encontros culturais. Segundo fontes do Instituto Brasileiro de Geografia e Estatística (IBGE) do ano de 2014, Recife é um município que, apesar de estar na zona urbana, é uma cidade que ainda apresenta características culturais de cidades interioranas. Os mercados de Recife visitados foram: Afogados, Água Fria, Beberibe, Boa Vista, Casa Amarela, Cordeiro, Encruzilhada, Madalena, Nova Descoberta, Pina, Santo Amaro, São José; os de Olinda: Peixinhos e Sítio Novo; além dos mercados das cidades vizinhas: Igarassu e Paulista..$^{(9,10)}$

Neste estudo foi realizada uma pesquisa de campo em todos os boxes que vendiam plantas medicinais e suas indicações terapêuticas. Assim, os responsáveis pelos boxes (raizeiros) foram questionados em horário comercial, nos próprios locais de trabalho, com entrevistas do tipo semi-estruturada, individuais, as quais, através da permissão prévia, o diálogo informal foi efetuado durante as visitas. Usuários do método alternativo também foram entrevistados a fim de investigar a frequência da utilização do uso das plantas medicinais, além da credibilidade e conhecimentos acerca do uso e seus possíveis danos.

As entrevistas com os raizeiros ou responsáveis pelos boxes de vendas das plantas medicinais foram transcritas para a Tabela 1 e Tabela 2, as quais contêm as principais plantas indicadas para o tratamento das cefaleias, bem como a forma de uso e informações adicionais cedidas.

As palavras-chave utilizadas para a revisão de literatura foram: "medicinal plants", "headache", "belief" and "Brazil"; além de "plantas medicinais", "dor de cabeça", "crenças" e "Brasil".

\section{RESULTADOS}

Na visita aos 17 Mercados Públicos (Recife: Afogaos, Água Fria, Beberibe, Boa Vista, Casa Amarela, Cordeiro, Encruzilhada, Madalena, Nova Descoberta, Pina, Santo Amaro, São José; Olinda: Peixinhos, Sítio Novo e Rio Doce; Igarassu e Paulista) foram entrevistados 24 raizeiros/responsáveis pelos boxes, apenas 18 recomendaram um total de 38 plantas medicinais, sendo apenas 16 delas $(42,1 \%)$ espécies nativas brasileira, enquanto que 22 eram originárias fora do Brasil (57,9\%). A Tabela 1 representa a frequência que as plantas recomendadas para 0 tratamento das cefaleias foram mencionadas pelos vendedores dos Mercados. Dos 24 raizeiros, 2 deles responderam "não tenho aqui, mas sei que existe", referindo-se ao seu desconhecimento acerca da devida indicação para o tratamento, mas ao mesmo tempo a crença de que havia planta medicinal para aquela enfermidade; e 4 deles relataram que recomendariam ao usuário a procura de farmácia para tratar de sua dor de cabeça.

Os entrevistados relatam ter o legado do conhecimento sobre as plantas medicinais como uma tradição familiar. Apenas um dos entrevistados, menciona que além da tradição e de seu negócio, que passaram de geração em geração, realizou também um curso de aprofundamento em plantas medicinais oferecido pela Universidade Federal Rural de Pernambuco (UFRPE). Apesar de 4 dos 24 raizeiros (16,67\%) referenciarem a farmácia para o tratamento da dor de cabeça, todos não só receitam as plantas para as enfermidades de seus clientes, como também as utilizam em casa e pretendem passar o conhecimento para os familiares mais jovens, a fim de perpetuar a cultura/negócio. Todos os vendedores acreditam na eficácia de seus produtos, bem como na benfeitoria que os produtos naturais trazem à vida dos consumidores, independente de estarem sob a forma de conservação e comercialização adequada, segundo a fiscalização que rege a segurança e qualidade da mercadoria. ${ }^{(11-14)}$

As plantas mencionadas na Tabela 2 podem ser encontradas no local para compra, consumo e conservação, como especiaria e algumas podem ser até mesmo cultivadas nas condições ambientais do local, apesar de terem origem em outras regiões/continentes, como mencionado na Tabela 1, mas que foram devidamente adaptadas nas condições climáticas do Brasil. ${ }^{(12,15)}$

A Tabela 2 retrata as diversas formas que os raizeiros/responsáveis pelos boxes dos Mercados indicam o uso das plantas. Pode-se perceber que, em alguns casos, não houve um consenso, havendo duas ou três formas de preparo e posologia. Nas entrevistas de natureza semiestruturada ainda pode-se averiguar que em nenhuma das recomendações houve alerta para possíveis contraindicações e toxidade da planta, nem 
de forma espontânea, nem quando questionado, verificando apenas acréscimos sobre os benefícios que as plantas poderiam trazer para outros possíveis problemas de saúde (anti-inflamatórios, antihipertensivos) ou comorbidades (ex. ansiedade e cefaleia; problemas no fígado e cefaleia).
Dos discursos dos raizeiros descritos na Tabela 2 pode-se ainda ressaltar a frequência dos métodos de tratamento pelo uso das plantas. Quanto ao tratamento por meio de "ingestão do chá", houve 34 citações, as quais eles recomendavam o tratamento por infusão ou decocção; o tratamento por "inalação" foi bem menos

Tabela 1 - As 38 plantas medicinais recomendadas para o tratamento das cefaleias e sua frequência de recomendação pelos raizeiros locais

\begin{tabular}{|c|c|c|c|}
\hline Nome comum & Nome científico & Frequência & Origem \\
\hline Colônia & Alpinia speciosa & 4 & Índia oriental \\
\hline Anador ou Chambá & Justicia pectoralis & 3 & Amazonas \\
\hline Anis estrelado & Illicium verum & 3 & China e Vietnã \\
\hline Babatenon ou Barbatimão & Stryphnodendron adstrigens (Mart.) Coville & 3 & Cerrado brasileiro \\
\hline Alecrim & Rosmarinus officinalis & 2 & Mediterrâneo \\
\hline Aroeira & Schinus molle $L$. & 2 & Sul do Brasil \\
\hline Camomila & Chamomilla recutita $(L)$. & 2 & Europa \\
\hline Capim santo & Cymbopogon citratus & 2 & Índia \\
\hline Erva cidreira & Melissa officinales & 2 & Europa \\
\hline Eucalipto & Eucalyptus & 2 & Oceania \\
\hline Gergelim & Sesamum indicum & 2 & Ásia tropical \\
\hline Hortelã-miúda & Mentha $\times$ piperita $L$ & 2 & China, Japão \\
\hline Sucupira & Pterodon pubescens Benth & 2 & Brasil \\
\hline Unha de gato & Uncaria tomentosa & 2 & Amazonas \\
\hline Alfazema ou lavanda & Lavandula officinalis & 1 & Ásia \\
\hline Amescla & Protium heptaphyllum & 1 & Amazonas \\
\hline Alfavaca de caboclo (majericão) & Ocimum gratissimum & 1 & África e Ásia tropical \\
\hline Arruda & Ruta graveolens L. & 1 & Europa Meridional \\
\hline Boldo & Plectranthus barbatus Andrews & 1 & Índia \\
\hline Cabacinha & Luffa operculata & 1 & América do Sul (Brasil) \\
\hline Caju roxo & Anacardium occidentale $L$. & 1 & América do Sul \\
\hline Cânfora & $\begin{array}{c}\text { Cinnamomun comphora (L.) } \\
\text { Nees \& Eberm. }\end{array}$ & 1 & $\begin{array}{c}\text { Ásia Oriental (Ilha de Formosa, Japão e } \\
\text { China Meridional) }\end{array}$ \\
\hline Caraíba & Tabebuia aurea & 1 & Amazonas \\
\hline Cáscara sagrada & Rhamnus purshiana & 1 & América do Norte \\
\hline Chá preto & Camellis sinensis & 1 & Ásia \\
\hline Cravo amarelo & Tagetes erecta Linn. & 1 & México \\
\hline Figueira & Ficus carica $L$. & 1 & Ásia \\
\hline Folha de amora & Morus alba $L$. & 1 & Ásia \\
\hline Gengibre & Zingiber officinale & 1 & Índia e China \\
\hline Jurubeba & Solanum paniculatum $L$ & 1 & Norte e Nordeste do Brasil \\
\hline Mentol & Mentha piperita & 1 & China, Japão \\
\hline Mulungú (casca) & Erythrina mulungu & 1 & Brasil \\
\hline Sálvia & Salvia divinorum & 1 & México \\
\hline Semente de manjerioba & Ocimum basilicum & 1 & Brasil \\
\hline Quina & Cinchona calisaya & 1 & Amazonas \\
\hline Quitoco & Pluchea Sagittalis & 1 & América do Sul \\
\hline Quixaba & Sideroxylon obtusifolium & 1 & Brasil: Piauí e Minas Gerais \\
\hline Uxi amarelo & Endopleura uchi (Huber) Cuatrec. & 1 & Amazonas \\
\hline
\end{tabular}


Tabela 2 - Indicação de plantas medicinais para tratar dores de cabeça e enxaquecas pelos raizeiros nos Mercados Públicos (Região Metropolitana de Pernambuco, Brasil)

\begin{tabular}{|c|c|c|c|}
\hline $\begin{array}{l}\text { Indicação para } \\
\text { dores de cabeça }\end{array}$ & Modo de preparo & Posologia & Observações \\
\hline Alecrim & $\begin{array}{l}\text { Mistura: Gengibre + alecrim: Corta pedacinhos } \\
\text { de gengibre e junta a um punhado de alecrim } \\
\text { para pôr na água já fervida (infusão). } \\
\text { Abafar a mistura e esperar cerca de } \\
10 \text { minutos para ingerir }\end{array}$ & $\begin{array}{l}\text { Ingerir o chá quando estiver } \\
\text { com a dor/na crise }\end{array}$ & - \\
\hline $\begin{array}{l}\text { Alfavaca de } \\
\text { caboclo } \\
\text { (majericão) }\end{array}$ & Infusão & Ingerir chá duas ou três vezes ao dia & - \\
\hline Alfazema & - & - & $\begin{array}{l}\text { Cedeu um "manual de } \\
\text { recomendações de uso de } \\
\text { plantas medicinais". } \\
\text { Não fez devidas } \\
\text { recomendações }\end{array}$ \\
\hline Amescla* & $\begin{array}{l}\text { Misturar: Cabacinha + Babatenon + Amescla + } \\
\text { Semente de Sucupira: Coloca todos os } \\
\text { ingredientes no álcool e deixa dois dias imerso }\end{array}$ & $\begin{array}{l}\text { Inalar quando sentir a } \\
\text { dor de cabeça }\end{array}$ & - \\
\hline $\begin{array}{l}\text { Anador ou } \\
\text { Chambá* }\end{array}$ & Decocção & Inalar à noite, antes de dormir. & - \\
\hline \multirow[t]{3}{*}{ Anis estrelado } & 1) Infusão & 1) Ingerir chá duas ou três vezes ao dia & - \\
\hline & 2) Decocção & 2) Ingerir o chá quando estiver na crise & \\
\hline & $\begin{array}{l}\text { 3) Misturar: camomila + anis estrelado: } \\
\text { Moer e amassar o anis estrelado, } \\
\text { juntar à camomila e ferver (decocção) }\end{array}$ & $\begin{array}{c}\text { 3) Ingerir chá } 1,2 \text { ou } 3 \text { vezes } \\
\text { durante o dia, a depender da dor, } \\
\text { até a dor passar }\end{array}$ & \\
\hline \multirow[t]{2}{*}{ Aroeira* } & $\begin{array}{l}\text { 1) Garrafada: babatenon + quixaba + caju roxo } \\
+ \text { unha de gato + aroeira + uxi amarelo }\end{array}$ & $\begin{array}{l}\text { 1) Ingerir chá duas vezes ao dia } \\
\text { uma quantidade de "três dedos" }\end{array}$ & $\begin{array}{l}\text { 1) Garrafada por } \\
\text { encomenda }\end{array}$ \\
\hline & 2) Misturar: Aroeira + Caraíba (decocção) & $\begin{array}{l}\text { 2) Ingerir chá duas ou três vezes ao dia, } \\
\text { dependendo da dor }\end{array}$ & $\begin{array}{l}\text { 2) "Os índios só tomam } \\
\text { esse chá - serve para todo } \\
\text { tipo de enfermidade" }\end{array}$ \\
\hline Arruda & - & Inalar a folha, quando dor & - \\
\hline \multirow{3}{*}{$\begin{array}{l}\text { Babatenon ou } \\
\text { Barbatimão* }\end{array}$} & 1) Infusão & 1) Ingerir chá duas ou três vezes ao dia & 1) Tomar morno \\
\hline & $\begin{array}{l}\text { 2) Garrafada: babatenon + quixaba + caju roxo } \\
+ \text { unha de gato + aroeira + uxi amarelo }\end{array}$ & $\begin{array}{l}\text { 2) Ingerir chá duas vezes ao dia uma } \\
\text { quantidade de "três dedos" }\end{array}$ & $\begin{array}{l}\text { 2) Garrafada por } \\
\text { encomenda }\end{array}$ \\
\hline & $\begin{array}{l}\text { 3) Misturar: Cabacinha + Babatenon + Amescla } \\
+ \text { Semente de Sucupira: } \\
\text { Coloca todos os ingredientes no álcool e } \\
\text { deixa dois dias imerso }\end{array}$ & $\begin{array}{l}\text { 3) Inalar quando sentir a } \\
\text { dor de cabeça }\end{array}$ & \\
\hline Boldo & Infusão & $\begin{array}{l}\text { Ingerir chá duas ou três vezes } \\
\text { ao dia }\end{array}$ & $\begin{array}{l}\text { Tomar morno. } \\
\text { "Muitos acreditam que dor } \\
\text { de cabeça vem do figado". }\end{array}$ \\
\hline Cabacinha* & $\begin{array}{c}\text { Misturar: Cabacinha + Babatenon + Amescla + } \\
\text { Semente de Sucupira: } \\
\text { Coloca todos os ingredientes no álcool e } \\
\text { deixa dois dias imerso }\end{array}$ & $\begin{array}{l}\text { Inalar quando sentir a } \\
\text { dor de cabeça }\end{array}$ & - \\
\hline Caju roxo* & $\begin{array}{c}\text { Garrafada: babatenon + quixaba + caju roxo + } \\
\text { unha de gato + aroeira + uxi amarelo }\end{array}$ & $\begin{array}{l}\text { Ingerir chá duas vezes ao dia uma } \\
\text { quantidade de "três dedos" }\end{array}$ & $\begin{array}{c}\text { Garrafada por } \\
\text { encomenda }\end{array}$ \\
\hline \multirow[t]{2}{*}{ Camomila } & 1) Infusão; & 1) Ingerir chá duas ou três vezes ao dia & 1) Calmante \\
\hline & $\begin{array}{l}\text { 2) Misturar: camomila + anis estrelado: } \\
\text { Moer e amassar o anis estrelado, } \\
\text { juntar à camomila e ferver (decocção) }\end{array}$ & $\begin{array}{c}\text { 2) Ingerir chá } 1,2 \text { ou } 3 \text { vezes } \\
\text { durante o dia, a depender da dor, } \\
\text { até a dor passar }\end{array}$ & \\
\hline
\end{tabular}


Tabela 2 (continuação) - Indicação de plantas medicinais para tratar dores de cabeça e enxaquecas pelos raizeiros nos Mercados Públicos (Região Metropolitana do Grande Recife, Pernambuco, Brasil)

\begin{tabular}{|c|c|c|c|}
\hline $\begin{array}{l}\text { Indicação para } \\
\text { dores de cabeça }\end{array}$ & Modo de preparo & Posologia & Observações \\
\hline Cânfora & Pomada caseira: mentol + cânfora & $\begin{array}{l}\text { Passar no local da dor, } \\
\text { massageando e/ou inalar }\end{array}$ & - \\
\hline Capim santo & Infusão & Ingerir chá duas ou três vezes ao dia. & Tomar morno/ tontura. \\
\hline Caraíba* & Misturar: Aroeira + Caraíba (decocção) & $\begin{array}{l}\text { Ingerir chá duas ou três vezes ao dia, } \\
\text { dependendo da dor }\end{array}$ & $\begin{array}{l}\text { "Os índios só tomam esse } \\
\text { chá - serve para todo tipo de } \\
\text { enfermidade" }\end{array}$ \\
\hline Cáscara sagrada & $\begin{array}{l}\text { Colocar as lascas de madeira em um copo } \\
\text { com água fria. Aproximadamente após } \\
10 \text { minutos, a "madeira solta a cor e } \\
\text { isso é a substância do medicamento" }\end{array}$ & $\begin{array}{l}\text { Ingerir goles do chá durante os } \\
\text { dias da crise }\end{array}$ & - \\
\hline Chá preto & Infusão & $\begin{array}{l}\text { Ingerir chá apenas quando } \\
\text { dor de cabeça }\end{array}$ & - \\
\hline Cravo amarelo & Infusão: adicionar folhas secas & Ingerir chá três vezes ao dia & - \\
\hline Colônia & $\begin{array}{l}\text { 1) Esquentar a folha e aplicar com } \\
\text { um pano na região da dor } \\
\text { 2) Infusão }\end{array}$ & $\begin{array}{l}\text { 1) Aplicar no local da dor } 2 \text { vezes ao dia } \\
\text { 2) Ingerir chá } 2 \text { ou } 3 \text { vezes ao dia até } \\
\text { passar a dor de cabeça ou coloca a folha } \\
\text { diretamente na região da cabeça que } \\
\text { está doendo: "a quentura da gente passa } \\
\text { para a folha junto com a dor" }\end{array}$ & - \\
\hline Erva cidreira & Infusão & Ingerir chá duas ou três vezes ao dia & - \\
\hline Eucalipto & Infusão ou decocção & $\begin{array}{l}\text { Ingerir chá duas ou três vezes ao dia } \\
\text { até passar a dor }\end{array}$ & Sinusite \\
\hline Figueira & - & - & $\begin{array}{l}\text { Cedeu um "manual de } \\
\text { recomendações de uso de } \\
\text { plantas medicinais" } \\
\text { Não fez devidas } \\
\text { recomendações }\end{array}$ \\
\hline Folha de amora & Infusão: colocar as folhas secas e abafar & Ingerir chá três vezes ao dia & - \\
\hline Gengibre & $\begin{array}{l}\text { Mistura: Gengibre + alecrim: Corta pedacinhos } \\
\text { de gengibre e junta a um punhado de alecrim } \\
\text { para pôr na água já fervida (infusão) } \\
\text { Abafar a mistura e esperar cerca de } \\
10 \text { minutos para ingerir }\end{array}$ & $\begin{array}{c}\text { Ingerir chá quando estiver com a } \\
\text { dor/na crise }\end{array}$ & - \\
\hline Gergelim & Torra o gergelim e faz o chá por decocção & Ingerir chá pela manhã e à noite & - \\
\hline \multirow[t]{2}{*}{ Hortelã-miúda } & 1) Decocção & $\begin{array}{l}\text { 1) Ingerir chá uma vez por dia } \\
\text { até a dor passar }\end{array}$ & $\begin{array}{l}\text { 2) Labirintite, } \\
\text { epilepsia em criança }\end{array}$ \\
\hline & $\begin{array}{l}\text { 2) Criança: Coloca num prato, mistura com } \\
\text { alho, bate com um garfo, sem ferver }\end{array}$ & 2) Ingerir, quando dor & \\
\hline
\end{tabular}

Jurubeba* alho, bate com um garfo, sem ferver

Cedeu um "manual de recomendações de uso de plantas medicinais". Não fez devidas recomendações 
Tabela 2 (continuação) - Indicação de plantas medicinais para tratar dores de cabeça e enxaquecas pelos raizeiros nos Mercados Públicos (Região Metropolitana do grande Reife, Pernambuco, Brasil)

\begin{tabular}{|c|c|c|c|}
\hline $\begin{array}{l}\text { Indicação para } \\
\text { dores de cabeça }\end{array}$ & Modo de preparo & Posologia & Observações \\
\hline Mulungú* & Decocção & Ingerir chá, quando dor & - \\
\hline Mentol & $\begin{array}{l}\text { Pomada caseira: } \\
\text { mentol +cânfora }\end{array}$ & $\begin{array}{l}\text { Passar no local da dor, } \\
\text { massageando e/ou inalar }\end{array}$ & - \\
\hline Quina* & - & - & $\begin{array}{l}\text { Cedeu um "manual de } \\
\text { recomendações de uso de } \\
\text { plantas medicinais". } \\
\text { Não fez devidas } \\
\text { recomendações }\end{array}$ \\
\hline Quitoco* & - & - & $\begin{array}{l}\text { Cedeu um "manual de } \\
\text { recomendações de uso de } \\
\text { plantas medicinais". } \\
\text { Não fez devidas } \\
\text { recomendações }\end{array}$ \\
\hline Quixaba* & $\begin{array}{c}\text { Garrafada: babatenon + quixaba + caju roxo + } \\
\text { unha de gato + aroeira + uxi amarelo }\end{array}$ & $\begin{array}{l}\text { Ingerir chá duas vezes ao dia uma } \\
\text { quantidade de "três dedos" }\end{array}$ & Garrafada por encomenda \\
\hline Sálvia & Infusão & $\begin{array}{l}\text { Ingerir xícara de chá de } \\
3 \text { a } 5 \text { vezes por dia }\end{array}$ & - \\
\hline $\begin{array}{l}\text { Semente de } \\
\text { manjerioba* }\end{array}$ & $\begin{array}{l}\text { Torra a semente e faz o } \\
\text { chá por decocção }\end{array}$ & $\begin{array}{l}\text { Ingerir uma xícara de manhã e } \\
\text { uma à noite }\end{array}$ & - \\
\hline Sucupira* & $\begin{array}{l}\text { 1) Quebra a casca, tira a semente e } \\
\text { faz o chá por infusão; } \\
\text { 2) Misturar: Cabacinha + Babatenon + Amescla } \\
\text { + Semente de Sucupira: Coloca todos os } \\
\text { ingredientes no álcool e deixa dois dias imerso }\end{array}$ & $\begin{array}{l}\text { 1) Ingerir chá } 3 \text { vezes por dia; } \\
\text { 2) Inalar quando sentir a dor } \\
\text { de cabeça }\end{array}$ & $\begin{array}{l}\text { 1) Serve para todo tipo de } \\
\text { dor, além de ser } \\
\text { anti-inflamatório }\end{array}$ \\
\hline Unha de gato* & $\begin{array}{l}\text { 1) Decocção } \\
\text { 2) Garrafada: babatenon + quixaba + caju roxo } \\
+ \text { unha de gato + aroeira + uxi amarelo }\end{array}$ & $\begin{array}{l}\text { 1) Ingerir chá quando dor } \\
\text { 2) Ingerir chá duas vezes ao dia uma } \\
\text { quantidade de "três dedos" }\end{array}$ & $\begin{array}{l}\text { Garrafada por } \\
\text { encomenda }\end{array}$ \\
\hline Uxi amarelo* & $\begin{array}{c}\text { Garrafada: babatenon + quixaba + caju roxo + } \\
\text { unha de gato + aroeira + uxi amarelo }\end{array}$ & $\begin{array}{l}\text { Ingerir chá duas vezes ao dia uma } \\
\text { quantidade de "três dedos" }\end{array}$ & $\begin{array}{l}\text { Garrafada por } \\
\text { encomenda }\end{array}$ \\
\hline
\end{tabular}

citado, destacando-se apenas 7 ervas; para "aplicação" na área com dor, apenas 3 indicações; e, sem informações adicionais, por não saberem recomendar a forma de uso, apareceram 5 recomendações. Muitas dessas indicações são dos mesmos raizeiros para plantas diversas, já que era comum a indicação de várias plantas pelo mesmo profissional.

\section{DISCUSSÃO}

Ainda hoje, devido a escassez de conhecimento e da formação dos profissionais especializados para $\circ$ diagnóstico e tratamento das cefaleias, os pacientes que sofrem de cefaleia ainda são inadequadamente tratados. ${ }^{(16)}$

A International Classification of Headache Disorders - second edition (ICHD-2, 2004) enumera 153 diagnósticos de cefaleias e subdivide os diagnóstico em cefaleias primárias e secundárias, entre outros tipos de cefaleias. ${ }^{(17)}$ Mas, em 2013, houve a implementação do ICHD-3 beta e, acredita-se que, com essa atualização, seja possível a melhor identificação de diagnósticos compatíveis com a Classificação Internacional de Doenças, versão 11 (CID11) e isso possa facilitar a correção de possíveis erros de versões anteriores e o melhor diálogo entre os profissionais da área. 
Os tipos mais comuns de cefaleia são a cefaleia do tipo tensional e a enxaqueca ou migrânea, ambas consideradas primárias. A cefaleia do tipo tensional é descrita como uma dor de cabeça tipicamente bilateral, não pulsátil, de intensidade fraca a moderada, podendo durar de minutos a alguns dias, não agravada após esforço físico, com rara presença, mas possível, de fono ou fotofobia (sem concomitância), e não apresenta náuseas. Já migrânea é uma doença incapacitante, representada pelo grande impacto na vida pessoal, podendo aparecer auras, principalmente visuais, a dor é tipicamente pulsátil e em apenas um lado da cabeça, com neuseas ou vômitos e foto e fonofobia. ${ }^{(18,19)}$

A dor de cabeça do tipo tensional é uma doença comum, com prevalência entre $30 \%$ e $78 \%$, com forte impacto pessoal e socioeconômico. Num estudo realizado com adultos com idade entre 18 e 65 anos apontou que a prevalência da enxaqueca pode variar entre $17 \%-21 \%$, os quais $8 \%-11 \%$ para o diagnóstico estrito de enxaqueca e 9\%-10\% para possíveis casos do diagnóstico, mas sempre com as mulheres apresentando predominância de 3:1. Nesse panorama, é demonstrado que $40 \%$ dos pacientes acometidos com migrânea nunca procuraram médicos para o tratamento da dor de cabeça e 60\% ignoram qualquer forma de tratamento, tornando-a uma doença subnotificada. ${ }^{(18,19)}$

Hoje, entende-se que o tratamento para cefaleias percorre desde os modelos medicamentosos, mais amplamente reconhecidos pelos estudos científicos em desenvolvimento exponencial, quanto pelos métodos mais tradicionais transculturais. Na história da medicina é evidenciado dois modelos comuns de intervenção no tratamento e prevenção de doenças: o modelo biomédico e a medicina complementar. $\bigcirc$ primeiro destacase como o modelo ocidental atual para as intervenções dos problemas de saúde e doenças mais difundido em regiões de maior desenvolvimento econômico. Porém, devido a superespecialização das áreas médicas, além da aparente dicotomia, negligência e falta de verba investida para esse cuidado, facilidade de aquisição de plantas medicinais, influência de tradição familiar, a medicina não convencional tem se intensificado desde a década de 1960 e levado as pessoas a se interessarem cada vez mais por formas alternativas de tratamento. Por causa desse ruído no campo da saúde e a fim de harmonizar os conflitos entre o modelo biomédico e os alternativos, no final de 1980, nos Estados Unidos e no
Reino Unido, foi adotado o termo "Medicina Complementar", a fim de compatibilizar o "elementar" (oriundo do modelo biomédico) com o "complementar" (oriundo das práticas alternativas), como forma de legitimar a prática secular. Na década de 1990, o termo "Medicina Integrativa" foi inserido a fim de descrever uma proposta que retratasse a integração dos diversos modelos terapêuticos, para além da lógica complementar, com o foco no cuidado integral da saúde - termo esse difundido nos demais países da América Latina. ${ }^{(6,11)}$

É neste contexto, onde a Medicina Integrativa ganha notoriedade na prevenção, tratamento e cura das doenças, que o mercado de plantas medicinais e medicamentos fitoterápicos continua em expansão. Consideram-se plantas medicinais as espécies vegetais que são naturais ou cultivadas com a finalidade terapêutica, com o intuito de curar ou aliviar enfermidades e, mais difundida em comunidades, podendo ser fresca (quando a coleta é realizada no momento do uso) ou seca (que faz uso após a coleta e secagem, também chamada de droga vegetal). $\bigcirc$ fitoterápico é o medicamento processado através da tecnologia, que tem como matéria-prima a planta medicinal, onde se extraem as substâncias ativas e seus derivados e, por ser industrializado, há uma maior padronização da quantidade e forma certa de utilização, o que permite maior segurança no uso. Os fitoterápicos já são reconhecidos pela OMS, a qual incentiva os países a regulamentar a utilização desses medicamentos. Assim, o desejo é ampliar as opções terapêuticas e fortalecer o uso da biodiversidade brasileira. ${ }^{15,20)}$

O site http://www.anvisa.gov.br/ da Agência Nacional de Vigilância Sanitária (Anvisa) - órgão público responsável por fortalecer a promoção da saúde da população - destaca a criação em 2008 do Programa de Plantas Medicinais e Fitoterápicos (PPMF), o qual explica e destaca a diferença entre os medicamentos fitoterápicos e as plantas medicinais. $O$ primeiro se utilizam de testes clínicos padronizados a fim de prezar pela segurança e eficácia da medicação; já algumas das plantas medicinais ganharam nova classificação e passaram a ser denominadas desde maio de 2014 como "produtos fitoterápicos tradicionais", os quais são assim denominados após a demonstração de uso seguro pelos seres humanos por um período de, no mínimo, 30 anos, além de embasamento literáriocientífico. 
A Anvisa listou apenas 43 plantas como produtos fitoterápicos tradicionais que são comumente usadas, ou seja, que não precisam de comprovação de eficácia e segurança e que não passam por processos tecnológicos para a sua utilização, mas necessitam de notificação e

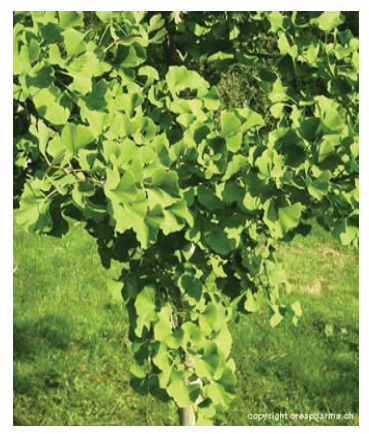

Ginkgo

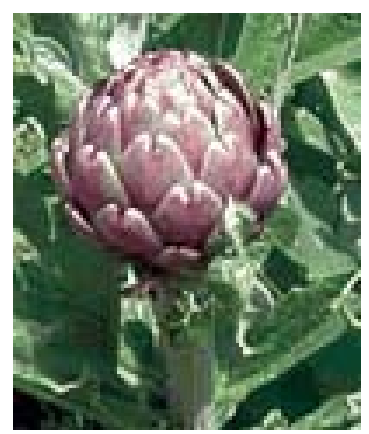

Alcachofra

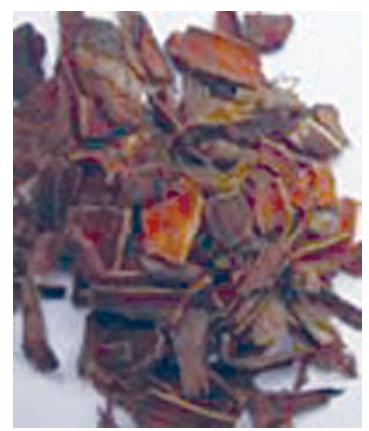

Cáscara sagrada

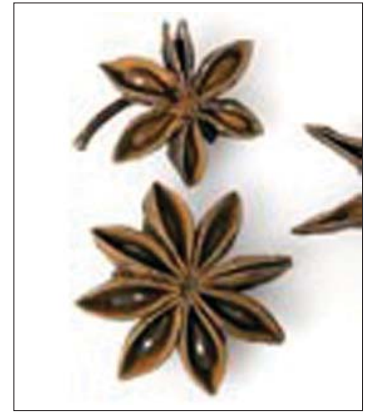

Anis estrelado

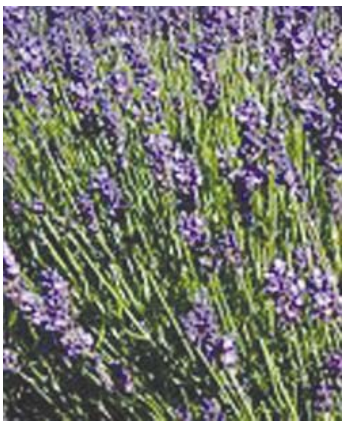

Lavanda

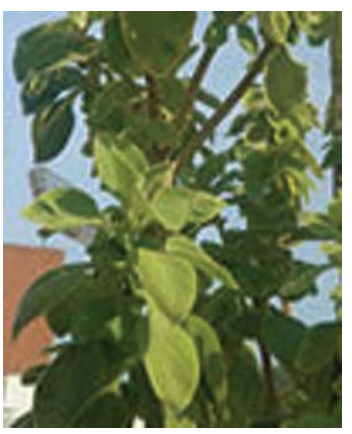

Boldo

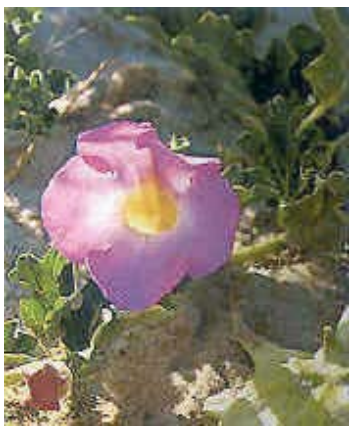

Garra-do-diabo

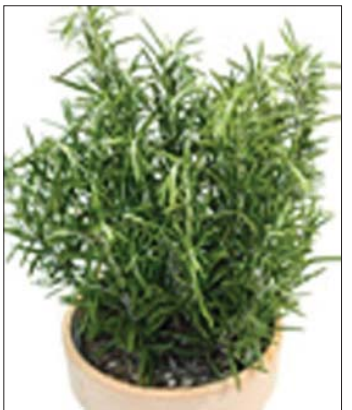

Alecrim

registro com forma de uso e medidas padronizadas para a sua comercialização legal; as mais utilizadas são: Aesculus hippocastanum (Castanha da índia), Mikania glomerata (Guaco), Ginkgo biloba (Ginkgo), Cynara scolymus (Alcachofra), Cassia angustifolia, Cassia senna e Senna alexandrina (Sene), Valeriana officinalis (Valeriana), Passiflora incarnata (Maracuiá), Peumus boldus (Boldo), Maytenus ilicifolia (Espinheira-Santa), Panax ginseng (Ginseng), Plantago psyllium (Psílio), Hypericum perforatum (Hipérico), Glycine max (Soja), Harpagophytum procumbens (Garra do diabo), Rhamnus purshiana (Cáscara sagrada).

Mas antes disso, no ano de 2006, o governo federal aprovou a Política Nacional de Plantas Medicinais e Fitoterápicos (PNPMF), a qual estabelece a garantia de segurança no uso das plantas medicinais e dos fitote-

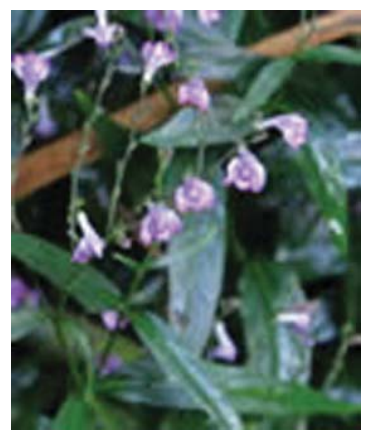

Anador

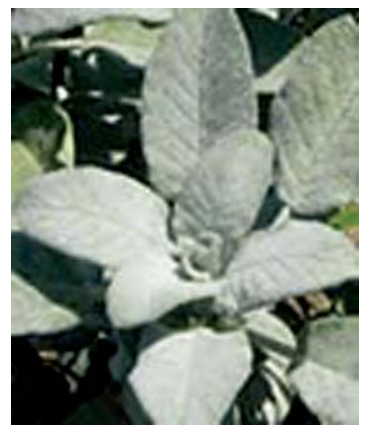

Sálvia

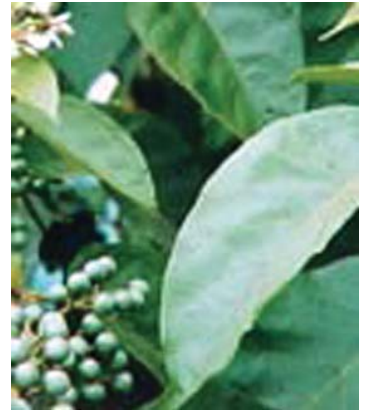

Jurubeba

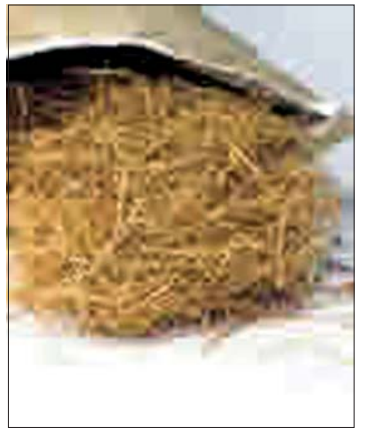

Unha de gato

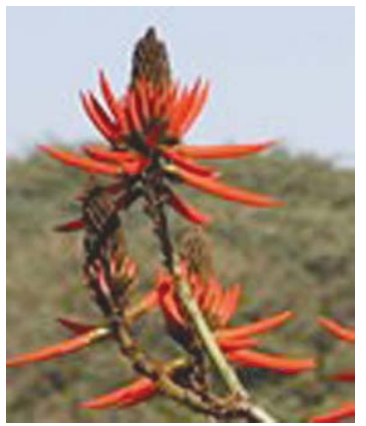

Mulungu

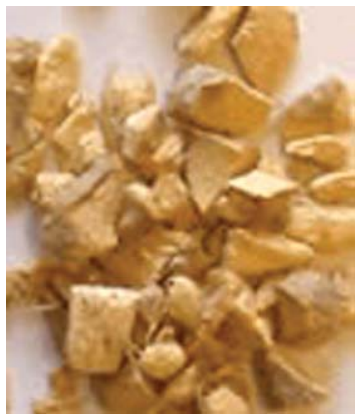

Ginseng 
rápicos no país, obedecendo critérios de padronização, os quais também fundamentou o programa de 2008 supracitado, permitindo a participação de todo os níveis do governo e da sociedade. A política embasa a implementação de fomentos para as bases tecnológicas e o uso racional de medicamentos, tanto de forma fitoterápica, quanto das plantas medicinais e seus derivados, ou seja, também categoriza e reconhece a importância do uso dos medicamentos ditos populares, manipulados em casa (considerados pela política como remédios caseiros de origem vegetal). ${ }^{(8)}$

Além de sistematizar e reconhecer o uso dos fitoterápicos, as políticas ratificam a utilidade e influências culturais, desde o costume da China antiga (3.000 a.C), dos europeus, índios e africanos até os dias atuais. ${ }^{(2)}$ Com a difusão e valorização do uso das plantas medicinais, que se tornava cada vez mais comum, cultura passada de geração para geração, surgia também a suposição de que os produtos naturais não apresentariam riscos para a saúde por serem da natureza. Contudo, o pensamento, que também transpassa gerações, não tem embasamento científico, - que oferece sérios riscos à saúde das pessoas que aderem à automedicação pelo tratamento alternativo. ${ }^{(5)}$

Avaliações e pensamentos constituem os processos cognitivos que afetam os substratos e vias neurais do sistema nervoso central, que podem subsidiar emoções e comportamentos, além de reações fisiológicas. Num processo retroalimentar, a biologia acaba por influenciar também os processos cognitivos, iá que as alterações neuroquímicas e a ativação das vias neurais podem alterar o funcionamento do cérebro. Ou seja, a resposta global (biológica e comportamental) diante de uma situação pode ser modificada ou concretizada de acordo com a crença que o indivíduo se apoia, formando padrões de interação que podem ser prolongados, mesmo que não façam sentido ou funcione de forma efetiva. ${ }^{(21)}$

As crenças são ideias que se consolidam com o tempo, em que as pessoas consideram mais válidas do que a lógica, podendo ter o cunho tendencioso, emocional, a qual a cognição humana se mostra eficiente e adaptativa segundo o traço cultural ao qual foi desenvolvida. A tendência com o passar das experiências e do tempo é o enraizamento de determinada ideia, fazendo com que o sujeito aceite mais facilmente conclusões que estejam de acordo com as opiniões e pensamentos previamente ensinados e formados, desenvolvendo portanto a crença. Nessa perspectiva há o viés da crença, que é a capacidade de distorção da lógica, tornando o julgamento tendencioso. A perseverança da crença também é um mecanismo bastante comum, o qual o indivíduo acredita com muita veemência em seus ideais, mesmo diante de alguma evidência contrária, podendo até gerar conflitos sociais. ${ }^{(22)}$

$\bigcirc$ uso das plantas medicinais, como algo mais comum e difundido, também ganha notoriedade pelas crenças populares que, por terem origens naturais, os consumidores estariam livre de possíveis efeitos colaterais/tóxicos ao organismo, comuns em medicamentos industrializados. A crença pode favorecer o julgamento tendencioso da melhora e a imunidade a possíveis efeitos colaterais que o uso indiscriminado poderia trazer ao indivíduo, contribuindo para a perseverança da crença. ${ }^{(23)}$

Sabe-se que a coleção de plantas medicinais é hoje empregada na terapia de diversos tipos de doença. Mas, em se tratando da prática de consumo para o tratamento/prevenção de doenças, o que se percebe é o cultivo próprio das especiarias ou a venda, através de pontos comerciais situados em mercados públicos. As maiores indicações das plantas são para as doenças de ordem respiratória e digestiva; dado este encontrado nos resultados dos trabalhos realizados no Brasil. Mas outras doenças entram no rol de uso, como é o caso da enxaqueca e dos outros tipos de dores de cabeça. Para essas enfermidades, referenciase a utilização de algumas plantas, catalogadas na Tabela 1, as quais também são utilizadas para outras enfermidades. ${ }^{(12)}$

Mercados públicos são locais de referência e um importante sistema de distribuição dos diversos tipos das plantas medicinais, onde são vendidas juntamente com outros artigos religiosos utilizadas em práticas de origens afro-brasileiras. Entretanto, muitas plantas são cultivadas e coletadas em torno das casas de culto ou em florestas, sendo esse o local de preferência para coleta dos usuários e ritualistas. No entanto, as plantas para serem utilizadas devem ser colhidas e manipuladas diretamente por uma autoridade religiosa, obedecendo ritos préestabelecidos. ${ }^{(7)}$

Um forte ponto comercial local é o Mercado de São José, no centro da Cidade do Recife, Pernambuco, localizado no Bairro de São José. O Mercado possui boxes de variedades de produtos. Há um foco de vendas das plantas medicinais, bem como de xaropes 


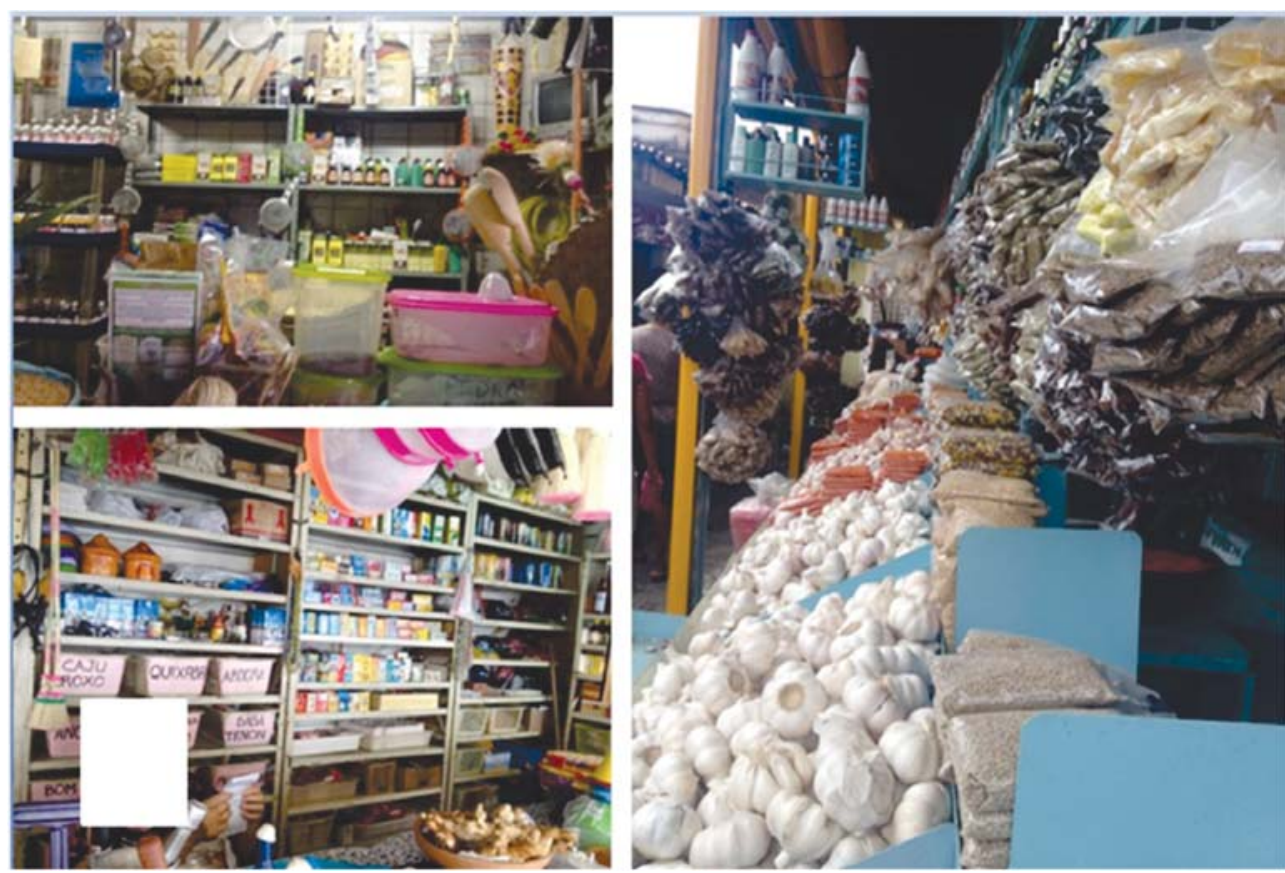

Boxes de venda de plantas medicinais. A - Mercado de Paulista; B - Mercado de Casa Amarela (Recife); C - Mercado de Igarassu.

e "garrafadas" (misturas de ervas para determinado fim terapêutico) produzidas pelos proprietários, os raizeiros. Estes alegam que a tradição vem de algumas religiões africanas (umbanda, por exemplo), além dos conhecimentos de gerações da família, tidos como valores que tem que se perpetuar. Assim como este modo de sabedoria é transmitido, os negócios de cunho econômicocultural acabam por ganhar destaque também.

O interesse da população pelas plantas (uso, costumes) perpetua muitas vezes de forma complementar, mas o interesse também aparece como preferência nos tratamentos das enfermidades, devido ao baixo custo e acesso. Porém as terapias naturais carecem de investigações e maiores referências consensuais que garantam a qualidade, eficácia e segurança do consumo e uso, a fim de tornar as indicações mais concisas e menos discrepantes. A validação científica acaba por repercutir também em certas propriedades que não são mencionadas na hora da compra da planta, que são os efeitos colaterais, caso seja utilizada de forma incorreta. E, apesar do foco da pesquisa ter sido as dores de cabeça, enxaqueca ou cefaleia, percebe-se que em campo e também na literatura, as plantas medicinais são indicadas para mais de uma enfermidade e muitas vezes para comorbidades. $(6,11,13,15,20,24)$

Essas plantas medicinais podem atuar atenuando a dor de cabeça por pelo menos dois mecanismos: (1) ação específica farmacológica sobre receptores, enzimas ou outras moléculas orgânicas e (2) por um efeito placebo.

Por exemplo, são encontrados pelo menos 18 componentes no óleo essencial da Alpinia speciosa (colônia, a mais indicada pelos raizeiros para tratar cefaleia neste estudo), e o óleo da planta inibiu o canal L-type $\mathrm{Ca}^{2+}$ utilizando o rato como modelo animal.(25) Efeito semelhante foi encontrado sobre este canal iônico com nifedipina, droga esta que já foi usada para tratar cefaleia. ${ }^{(26,27)}$ Colônia também é usada para tratar sintomatologia neuropsiquiátrica como depressão, estresse e ansiedade (comorbidades de enxaqueca). ${ }^{(28)}$ Em um estudo de cinco componentes da planta foram isolados - p-cymene $(28.0+/-5.0 \%), 1,8$-cineole $(17.9+/-4.2 \%)$, terpinen-4-ol (1 1.9+/- 6.3\%), limonene $(6.3+/-2.2 \%)$ e camphor $(5.2+/-2.1 \%)$. Inalação do óleo da planta provocou ansiedade em camundongos, que foi atenuado por fluoxetina. ${ }^{(28)}$

Segundo Benedetti (29) o termo placebo é erroneamente definido farmacologicamente como uma substância inerte sem ação farmacológica. Benedetti insiste que o conceito de placebo é mais complexo, alem da substancia inclui também o ritual, as palavras usadas ou ouvidas, o simbolismo e outros significados que acompanham o uso da substância ou tratamento escolhido ou oferecido ao paciente. 


\section{CONCLUSÃO}

Há uma gama de variedade de plantas medicinais recomendadas pelos raizeiros da região metropolitana da cidade do Recife, que administram e recomendam as plantas das mais diversas formas e em muitos momentos para mais de uma enfermidade, sem critérios de contraindicação, inclusive. Faz-se necessário, então, a acurácia e a unicidade de informações, bem como a padronização dos dados das plantas medicinais que são comercializadas, a fim de tornar o envolvimento das práticas alternativas/integrativas algo validado e fidedigno a sua proposta de intervenção, como os programas que a Anvisa fomenta. Cabe aos profissionais de saúde que trabalham com o modelo biomédico não ignorar essa prática, de modo a tornar as práticas de modo consensual para que o paciente seja tratado devidamente e com as informações que necessita, sem maiores danos para a saúde.

\section{REFERÊNCIAS}

1. Koehler PJ, Boes CJ. A history of non-drug treatment in headache, particularly migraine. Brain [Internet]. 2010 Aug [cited 2014 Dec 8];133(Pt 8):2489-500. Available from: http:// www.ncbi.nlm.nih.gov/pubmed/20639545

2. McGovern PE, Mirzoian A, Hall GR. Ancient Egyptian herbal wines. Proc Natl Acad Sci U S A [Internet]. 2009 May 5; 106 (18):7361-6. Available from: http://www. pubmedcentral. nih. gov/articlerender.fcgi? artid $=2678600 \&$ tool $=$ pmcentrez\& rendertype $=$ abstract

3. Halberstein R a. Medicinal plants: historical and cross-cultural usage patterns. Ann Epidemiol [Internet]. 2005 Oct [cited 2014 Dec 3]; 15(9):686-99. Available from: http://www.ncbi. nlm.nih. gov/pubmed/15921929

4. Pinto AC, Silva DHS, Bolzani V da S, Lopes NP, Epifanio R de A. Produtos naturais: atualidade, desafios e perspectivas. Química Nova. 2002. p. 45-61.

5. Conselho Regional de Farmácia do Estado de São Paulo. Plantas medicinais e fitoterápicos. 2a ed. São Paulo; 2011.

6. Menezes VA de, Anjos AGP dos, Pereira MRD, Leite AF, GranvilleGarcia AF. Terapêutica com Plantas Medicinais: Percepção de Profissionais da Estratégia de Saúde da Família de um Município do Agreste Pernambucano. Odonto. 2012;20 (39): 111 -22.

7. Albuquerque UP De. The use of medicinal plants by the cultural descendants of african people in Brazil. Acta Farm Bonaer. 2001; 20(2): 139-44.

8. Ministério da Saúde. Programa nacional de plantas medicinais e fitoterápicos. la ed. Brasília; 2009.

9. IBGE Instituto Brasileiro de Geografia e Estatística [Internet]. 2014 [cited 2014 Apr 16]. Available from: http:// cod.ibge.gov.br/232X9
10. Secretaria de serviços públicos de Recife [Internet]. [cited 2014 Apr 16]. Available from: http://www.recife.pe.gov.br/pr/ servicospublicos/csurb/mercados.html

11. Aparecida M, Otani P. A Medicina Integrativa e a construção de um novo modelo na saúde. Cien Saude Colet. 2011 ; 16(3): $1801-11$.

12. Oliveira GL, Oliveira AFM AL. Plantas medicinais utilizadas na comunidade urbana de Muribeca, Nordeste do Brasil. Acta Bot Brasilica. 2010;24(2):571-7.

13. Melo JG De, Martins JDG da R, Amorim ELC de, Albuquerque UP de. Qualidade de produtos a base de plantas medicinais comercializados no Brasil: castanha-da-índia (Aesculus hippocastanum L .), capim-limão (Cymbopogon citratus (DC .) Stapf) e centela (Centella asiatica (L .) Urban ) 1. Acta Bot Brasilica. 2007;21 (1):27-36.

14. Ministério da Saúde. Política Nacional de Plantas Medicinais e Fitoterápicos. la edição. Brasília; 2006.

15. Cabral JA de L, Maciel JR. Levantamento etnobotânico da coleção de plantas medicinais do Jardim Botânico do Recife, PE. BioFar Rev Biol e Farmácia. 2011 ;6(2):121-9.

16. The World Health Organization. Atlas of headache disorders and resources in the world 2011 [Internet]. World Health Organization. 2011 p. 72. Available from: http:// www. who.int/mental_health/management/ atlas_headache_disorders/en/

17. Carvalho DS. Tratamento das cefaleias baseado em evidências. Diagn Trat. 2009; 14(1):12-8.

18. Lanteri-Minet M, Valade D, Geraud G, Lucas C, Donnet A. Revised French guidelines for the diagnosis and management of migraine in adults and children. J Headache Pain [Internet]. 2014 Jan; 15(1):2. Available from: http://www.pubmedcentral.nih.gov/ articlerender.fcgi? artid $=3905961$ \&tool=pm centrez\& rendertype $=$ abstract

19. The International Classification of Headache Disorders, 3rd edition (beta version). [Internet]. Cephalalgia?: an international journal of headache. 2013 [cited 2014 May 27]. p. 629-808. Available from: http://www.ncbi.nlm.nih.gov/pubmed/ 23771276.

20. Firmo W da CA, Menezes VAM de, Passos CE de C, Dias CN, Alves LPL, Dias ICL, et al. Contexto histórico, uso porpular e concepção científica sobre plantas medicinais. Cad Pesq. $2011 ; 18($ n. especial):90-5.

21. Sudak DM. Terapia Cognitivo-Comportamental na Prática. 1a ed. Porto Alegre; 2008.

22. Myers DG. Psicologia. In: LCT, editor. 7a edição. Rio de Janeiro; 2006. p. 281 - 305.

23. Moreira HS, Vasconcellos MB, Alves ER, Santos FM, Saiki M. Elemental composition of herbal medicines sold over-thecounter in São Paulo city, Brazil. J Radioanal Nucl Chem. 2011 ; 290(3):615-21.

24. Nascimento VT, Lacerda EU, Melo JG, Lima CSA, Amorim ELC AU. Controle de qualidade de produtos à base de plantas medicinais comercializados na cidade do Recife-PE: erva-doce (Pimpinella anisum L.), quebra-pedra (Phyllanthus spp.), espinheira santa (Maytenus ilicifolia Mart.) e camomila (Matricaria recutita). Rev Bras Plantas Med. 2005;7(3):56-64. 
25. Santos BA, Roman-Campos D, Carvalho MS, Miranda FM, Carneiro DC, Cavalcante PH, Cândido EA, Filho LX, Cruz JS, Gondim AN. Cardiodepressive effect elicited by the essential oil of Alpinia speciosa is related to L-type $\mathrm{Ca}^{2+}$ current blockade. Phytomedicine. 2011 May 15;18(7):539-43.

26. Pareja JA, Sjaastad O. Primary stabbing headache. Handb Clin Neurol. 2010;97:453-7.

27. Jacome DE. Exploding head syndrome and idiopathic stabbing headache relieved by nifedipine. Cephalalgia. $2001 ; 21$ (5):617-8.

28. Murakami S, Matsuura M, Satou T, Hayashi S, Koike K. Effects of the essential oil from leaves of Alpinia zerumbet on behavioral alterations in mice. Nat Prod Commun. 2009;4(1):129-32.

29. Benedetti F. Placebo and the New Physiology of the DoctorPatient Relationship Physiol Rev. 2013; 93(3):1207-46.

Correspondência

Amanda Araújo da Silva

Programa de Pós-graduação em Neuropsiquiatria e

Ciências do Comportamento, Departamento de Neuropsiquiatria

Universidade Federal de Pernambuco

Cidade Universitária,

Recife, PE, Brasil

e-mail: amanda-aas@hotmail.com

Recebido: 2 de junho 2014

Aceito: 20 de junho 2014 